\title{
Potential Multidrug Interactions in Elderly Ambulatory Patients
}

\author{
Tara Anand ${ }^{1}$, Brendan Wallace ${ }^{1}$, and Herbert Chase $^{1}$ \\ ${ }^{1} \mathrm{CUMC}$
}

November 18, 2020

\begin{abstract}
Aim. Polypharmacy may increase the prevalence of potential multidrug interactions (pMDIs), where one drug interacts with two or more other drugs, possibly amplifying the risk of a potential adverse drug event (pADE). The major goal of this study was to estimate the prevalence of amplifying pMDIs in an ambulatory cohort of older patients. Methods. Current medication lists of 22033 randomly chosen outpatients [?]50 years old were extracted from the New York Presbyterian Hospital (NYP) data warehouse. Network analysis identified patients prescribed three or more interacting drugs from their current medication lists. Potentially harmful interactions were identified from the NYP drug-drug interaction alerting system. pMDIs were considered amplifying if the interactions increased the probability of a pADE through pharmacokinetic, pharmacodynamic or conditional mechanisms. Results. pMDIs were identified in 5.1\% of the medication lists; $3.4 \%$ were three-drug and $1.1 \%$ were four-drug pMDIs. The most common drugs involved were psychotropic, comprising $23.3 \%$ of the total drugs. The most common pADEs associated with the interactions were serotonin syndrome (17.2\%), seizures (14.4\%), prolonged QT interval (15.8\%) and bleeding (14.4\%). pADE amplification risk was identified in $71.8 \%$ of three-drug pMDIs when one drug interacted with two others, $97.8 \%$ when all three interacted with each other, and $93 \%$ for four-drug pMDIs. Conclusion. Our data suggest that approximately $5 \%$ of elderly ambulatory patients may be exposed to pMDIs which amplify the probability of associated adverse drug events. The recent and persistent rise in polypharmacy will likely increase the prevalence of pMDIs and potential exposure to serious adverse events.
\end{abstract}

Potential Multidrug Interactions in Elderly Ambulatory Patients

Tara V. Anand, BA ${ }^{1}$, Brendan K. Wallace, $\mathrm{BS}^{2}$, and Herbert S. Chase, MD, $\mathrm{MA}^{1^{*}}$

${ }^{1}$ Department of Biomedical informatics, Columbia University Medical Center; ${ }^{2}$ Vagelos College of Physicians and Surgeons, Columbia University, New York, NY 10032 USA

*Corresponding author: email hc15@cumc.columbia.edu

\section{ABSTRACT}

Aim. Polypharmacy may increase the prevalence of potential multidrug interactions (pMDIs), where one drug interacts with two or more other drugs, possibly amplifying the risk of a potential adverse drug event (pADE). The major goal of this study was to estimate the prevalence of amplifying pMDIs in an ambulatory cohort of older patients.

Methods. Current medication lists of 22033 randomly chosen outpatients [?]50 years old were extracted from the New York Presbyterian Hospital (NYP) data warehouse. Network analysis identified patients prescribed three or more interacting drugs from their current medication lists. Potentially harmful interactions were identified from the NYP drug-drug interaction alerting system. pMDIs were considered amplifying if the interactions increased the probability of a pADE through pharmacokinetic, pharmacodynamic or conditional mechanisms. 
Results. pMDIs were identified in $5.1 \%$ of the medication lists; $3.4 \%$ were three-drug and $1.1 \%$ were fourdrug pMDIs. The most common drugs involved were psychotropic, comprising $23.3 \%$ of the total drugs. The most common pADEs associated with the interactions were serotonin syndrome (17.2\%), seizures (14.4\%), prolonged QT interval (15.8\%) and bleeding (14.4\%). pADE amplification risk was identified in $71.8 \%$ of three-drug pMDIs when one drug interacted with two others, $97.8 \%$ when all three interacted with each other, and $93 \%$ for four-drug pMDIs.

Conclusion. Our data suggest that approximately $5 \%$ of elderly ambulatory patients may be exposed to pMDIs which amplify the probability of associated adverse drug events. The recent and persistent rise in polypharmacy will likely increase the prevalence of pMDIs and potential exposure to serious adverse events.

1. What is already known about this subject

The steady rise in polypharmacy in elderly patients has increased the prevalence of serious adverse events resulting from drug-drug interactions.

It has been hypothesized that polypharmacy will also increase the prevalence of multidrug interactions where one drug interacts with two or more, potentially amplifying the probability of an adverse event.

2. What this study adds:

Using network analysis, we determined that $5 \%$ of the medication lists of a cohort of elderly ambulatory patients contained three and four-drug multidrug interactions with amplification potential.

Psychotropic drugs were most often involved in multidrug interactions, placing patients at risk for serotonin syndrome, prolonged QT interval or seizures.

\subsection{INTRODUCTION}

For several decades there has been a concerted effort to identify potentially harmful drug-drug interactions and to develop and implement decision support prompts to warn prescribing clinicians of these possible interactions. Drug-drug interactions are an increasingly common cause of morbidity and mortality in the elderly, accounting for nearly $5 \%$ of hospital admissions from the emergency room [1]. The steady increase in polypharmacy in the elderly population, resulting in an average of five drugs per patient [2,3], increases the likelihood that a patient will experience one or more adverse events due to a drug-drug interaction $[4$, $5]$.

Most of the research efforts to identify the impact of drug-drug interactions have focused on two-drug interacting pairs. With the increasing prevalence of polypharmacy, however, there is an effort to identify potential multidrug interactions (pMDIs), where one drug interacts with two or more other drugs, and their potential to amplify the probability of an adverse event $[6,5,7]$. A patient taking four drugs, for example, could be exposed to two different adverse events associated with two-drug interacting pairs if the pairs acted independently from one another. However, if each of the four drugs interacted with all others, the potential for patients to experience serious adverse events could be significantly amplified if several of the drugs were associated with the same adverse event or if two or more drugs altered the metabolism of the other drugs in the multidrug interaction.

Although several studies have explored the prevalence of potential two-drug interactions in elderly ambulatory patients, there are few studies of multidrug interactions and the potential consequences [8,9]. The major goals of this study were to estimate the prevalence of multidrug interactions in an ambulatory cohort of older patients, to identify the most common drugs involved in the interactions, to identify the potential serious adverse events associated with the interactions and to identify mechanisms by which the interactions could lead to amplification of the risk of associated adverse events. We explored these issues by analyzing the current medication lists of individual ambulatory patients cared for at the New York Presbyterian Hospital (NYP), using network analysis to identify multidrug interactions and natural language processing to identify the potential adverse events associated with the interactions from the NYP drug-drug interaction database. 


\subsection{METHODS}

2.1 Source of patient data. The current medication lists of 22033 randomly chosen outpatients from 20152020, were extracted from the NYP data warehouse. The dates of the oldest and newest prescriptions on the medication list were within a five-year time window or shorter. Medications were recorded with either generic or brand names, which were converted to generic names. Topical and ophthalmic preparations were excluded. Patients prescribed any of the following medications were excluded because these drugs are largely prescribed to hospitalized patients: lactulose, enoxaparin, vancomycin, neomycin, dalteparin, or heparin. The study was approved by the Columbia University Irving Medical Center institutional review board (protocol AAAC8273).

2.2 List of potential two-drug interacting pairs. The NYP hospital system utilizes a decision support tool (Allscripts) that consults a list of potential two-drug interactions from a Cerner Multum table modified by NYP [10]. The severity of the potential drug interactions is graded from one to seven: 1- contraindicated, 2- generally avoid; 3- monitor closely; 4- adjust dosing interval; 5- adjust dose; 6- additional contraception recommended; 7-might be a potential drug-drug interaction (pDDI). For this study we extracted those interactions that were graded 1,2 and 3 .

2.3 Identification of multidrug interactions. pMDIs and associated potential adverse events (pADEs) were identified by finding interacting two-drug pairs on patients' medication lists and then determining whether there were drugs that participated in more than one drug-drug interaction (overlapping interacting drug-drug pairs) using network analysis and standard depth-first search graph traversal [11]. Drugs in this list were represented as the network nodes and potential interactions between the drugs as the edges. The algorithm determined an individual network for each patient's medication list and identified multidrug interaction sub-graphs, if present. The steps involved are described in Fig. 1

2.4 Identification of pADEs associated with pMDIs. A master table of significant potential adverse events was developed through manual review of a selection of NYP database pDDI descriptors. Potential adverse events were identified for each of the drug-drug pairs that comprised the pMDI by parsing the description of the interaction in the NYP tables and determining if an adverse event listed in the master table appeared in the description using regular expressions. A pADE associated with a drug-drug pair was identified as a "pADE-instance."

2.5 Amplification. Multidrug interactions were classified as either amplifying or non-amplifying. In amplifying and non-amplifying pMDIs, the pADEs are the collection of the individual pADEs associated with each drug-drug pair. However, in amplifying pMDIs, the probability of pADEs is greater than the probability of the pADE associated with the drug-drug pair in isolation because of the multiple interactions between the drugs. We explored three mechanisms of amplification: pharmacodynamic, where the pMDI is composed of two or more drug-drug interactions which are associated with the same pADE; pharmacokinetic, where two or more drugs inhibit the metabolism of a third or fourth; and conditional, where two or more drugs alter the patient's physiology, increasing the risk of a pADE caused by a third or fourth drug.

\subsection{RESULTS}

3.1 Potential multidrug interactions. The medication lists of 22033 randomly chosen outpatients from the NYP data warehouse had a mean age of 72.5 (SD 8.2) of which $53 \%$ were female. Of these patients 5142 $(23.3 \%)$ were exposed to at least one pDDI pair, 3369 (15.2\%) were exposed to only one pDDI pair, and $1773(8.0 \%)$ were exposed to two or more pDDI pairs (Table 1$)$. The number of drugs participating in all pDDIs for a given patient (Table 1, "Actual," third column from right) was lower than that required if the pDDI pairs were independent of each other, where each drug interacted with only one other drug (Table 1, "Expected," fourth column from the right). In patients exposed to five pDDIs the average number of drugs participating in the pDDIs was 5.71 (SD 1.31), approximately half of the ten drugs necessary if participating drugs interacted with only one other drug. The higher the number of prescribed drugs on a medication list (Table 1, "\# drugs on medication list") the greater the proportion (\%) of drugs involved in a pDDI (Table 1 , "\% all drugs participating in a DDI"). 
3.2. Potential multidrug interactions. We used network analysis to count the number of multidrug interactions in 1129 patients with at least one multidrug interaction. There were $752(66.6 \%)$ three-drug interactions (Table 2, column "3"). In 610 pMDIs one drug interacted with two other drugs (Table 2, line "2", column " 3 "). In 142 pMDIs all three drugs interacted with each other (line "3", column "3", Table 2). There were 233 $(20.6 \%)$ four-drug interactions (Table 2, column "4"). Most commonly, one drug interacted with three others (150 of 233). There were also four-drug pMDIs that resulted in four, five or six interactions. In fourteen of the four-drug pMDIs and one five-drug pMDI, all drugs interacted with each other forming a complete graph.

3.3 Drugs involved in multidrug interactions. A total of 277 unique drugs were involved in pMDIs. The top 15 most common drugs involved in over $40 \%$ of the interactions and their associated drug classes are listed in Table 3. Although the classes of participating drugs were diverse, psychotropic drugs were the most involved representing $23 \%$ of the total number of interactions of the top 50 drugs. The main psychotropic drugs involved in pMDIs were bupropion, escitalopram and trazadone (Table 3).

3.4. Potential adverse events associated with multidrug interactions. The most common pADEs were serotonin syndrome, seizures, prolonged QT and bleeding (Table 4). Of the 1129 pMDIs, there were 2222 pADE-instances demonstrating that some of the drug-drug pairs in a pMDI were associated with more than one pADE, the most common of which were [seizures-serotonin syndrome], [seizures-prolonged QT], and [prolonged QT-serotonin syndrome]. Psychotropic drugs accounted for over $40 \%$ of the total drugs involved in these pMDIs.

A significant proportion of pMDIs had two or more drug-drug pairs associated with the same pADE. In the three and four-drug pMDIs, $76.9 \%$ and $92.7 \%$ were associated with two or more instances of the same pADE, respectively (Table 5). The pMDIs in patients $\mathrm{A}, \mathrm{B}$ and $\mathrm{C}$ in Table 6 , for example, were exposed to three pADE-instances associated with bleeding, serotonin syndrome and prolonged QT, respectively. In patients with four-drug pMDIs, 96 of the $233(41.2 \%)$ contained two pADE-instances of two different adverse events.

Of the 1127 pMDIs, $47 \%$ contained drugs that inhibited the metabolism of the other drugs. Of the fourdrug interactions in which the pMDI included two pADE-instances of two different adverse events, over $40 \%$ contained two or more drugs that inhibited the metabolism of the other drugs. Patients D, E, G and H of Table 6 are examples of the pMDIs which included drugs that could increase the concentration of the other drugs associated with pADEs. Patient $\mathrm{E}$ has been prescribed warfarin and aspirin which place the patient at risk for hemorrhage. The patient has also been prescribed amiodarone and metronidazole, both of which inhibit the metabolism of warfarin, thereby further amplifying the risk of bleeding.

Approximately $10 \%$ of the 1127 pMDIs contained conditional interactions. Patients G and $\mathrm{H}$ (Table 6) were exposed to drugs that lower the seizure threshold increasing the likelihood of bupropion-induced seizures. The risk is further amplified by bupropion's inhibition of the metabolism of the other drugs. Patient F was exposed to two drugs, hydrochlorothiazide and furosemide, which by causing hypokalemia, would increase the probability of prolonged QT caused by amiodarone and ranolazine. Of the four-drug interactions in which the pMDI included two pADE-instances of two different adverse events, in $9.3 \%$ of the pMDIs the four drugs consisted of two diuretics (loop and thiazides) and one or two drugs associated with prolonged QT.

3.5 Amplification of potential pADEs. We counted the number of pMDIs where pADEs could be amplified either as a result of pharmacodynamic, pharmacokinetic, or conditional mechanisms, or a combination of the three. In the three-drug pMDIs where one drug interacted with two others, pADE amplifications were seen in $71.8 \%$. When all three drugs interacted with each other, $97.8 \%$ of the pMDIs were potentially amplified. Of 233 four-drug pMDIs, $93 \%$ of the interactions could result in amplification. The most common amplified pADEs were serotonin syndrome, prolonged QT, and seizures.

\subsection{DISCUSSION}

4.1. Potential multidrug interactions. Given the rising prevalence of polypharmacy, patients are likely to be at increased risk for experiencing adverse events due to multidrug interactions where one or more drugs 
interact with two or more other drugs [6]. The goal of this project was to establish that patients prescribed multiple medications are at risk for pMDIs, to identify the pADEs associated with the interactions, and determine to what extent risk of pADEs might be amplified by the multiple interactions amongst the drugs. Using network analysis of individual patient's medication lists, we demonstrated multidrug interactions in $1129(5 \%)$ of the 22033 randomly chosen mediation lists from an older cohort of ambulatory patients. The majority $(67 \%)$ of pMDIs were observed in patient taking three drugs, where one drug interacted with two other drugs or all three interacted with each other (Table 2). Patients with four-drug interactions comprised $20 \%$ of the pMDIs where there were between three and six connections between the drugs. A small percentage of the pMDIs (12\%) were identified in patients taking five to ten drugs resulting in four to 13 interactions.

4.2 Amplification of risk. The rationale for identifying pMDIs was based on the hypothesis that overall risk of pADEs would be amplified as a result of the multiple interactions and be greater than the combined risks associated with the individual drug-drug pairs that comprised the pMDI. We reviewed the pMDIs to identify potential amplifications defined as multiple drugs with the same pADE (pharmacodynamic), combinations of interacting drugs which included those that reduced the metabolism of the other drugs (pharmacokinetic) and combinations where one or more drugs altered the patient's physiology, increasing the probability of experiencing a pADE associated with the other drug (conditional). We found that the majority of pMDIs were comprised of combinations that could result in amplified risk of associated pADEs. In the three-drug pMDIs, pADE amplifications were seen in $71.8 \%$, where one drug interacted with two others, and $97.8 \%$ when all three drugs interacted with each other. In four-drug pMDIs, $93 \%$ of the interactions could result in amplification. Examples of potentially amplifying interactions are presented in Table 6.

4.3 Psychotropic medications. Drugs for psychiatric conditions were the most frequently involved in multidrug interactions, accounting for $23.3 \%$ of the drugs involved (Table 3). Several prior studies of two-drug interacting pairs made similar observations $[12-17,8]$. The preponderance of psychotropic drugs in multidrug interactions may reflect the rising incidence of psychotropic polypharmacy [18]. Many psychotropic medications pose a dual risk in that they are potent inhibitors, substrates, or both of CYP 1A2, 2D6 and CYP 3A4 as well as associated with potentially lethal pADEs, such as serotonin syndrome and torsades de pointe $[19,20]$. Fluvoxamine has been shown to inhibit four CYP450 enzymes (1A2, 2C19, 2D6 and 3A4) all of which are involved in the metabolism of other psychotropic drugs [21, 22]. Age-related changes in pharmacokinetics in the elderly make them especially sensitive to these interactions [23]. Increasing the levels of substrate drugs which are involved in a pharmacodynamic pMDIs to prolong the QT will further amplify the risk of torsades de pointes given the additive effect on the QT interval for each drug [24]. The high prevalence of involvement of psychotropic drugs is particularly worrisome given the known association between psychotropic medication and an increased risk of death [25-32].

\subsection{Relationship between actual and potential multidrug interactions.}

While there are many studies of the prevalence of patients who are prescribed drugs that participate in potential drug-drug interactions, there are limited studies of the prevalence of documented adverse events that result from multidrug interactions in ambulatory patients [33, 34, 15, 35, 8]. Multidrug interactions are expected in hospitalized patients who are acutely ill and are treated with multiple medications. A majority of patients in the intensive care units experience drug-drug related adverse events [33, 36-38]. Hospitalized patients, especially those in the ICU, are monitored for adverse events, such as QT prolongation or hemorrhage and can promptly receive appropriate interventions. Ambulatory patients, prescribed multiple drugs for chronic conditions, who experience adverse reactions due to multidrug interactions would do so outside of the hospital and be unaccounted for if they were to suffer a lethal reaction.

There are currently no studies that have prospectively followed patients with potential multidrug interactions to determine the proportion that actually develop adverse events predicted by the interactions and mechanisms of interaction. However, the FDA adverse events reporting system (FAERS) has recently been mined to identify multidrug interactions and the resulting adverse events experienced by patients [7]. Two of the five examples of multidrug interactions and associated adverse events were composed of three psychotropic medications. One of the two MDIs was associated with a cardiovascular event. While this approach can- 
not determine the prevalence of the multidrug associated adverse events, it can establish that the potential multidrug interactions are associated with documented serious adverse events.

\subsection{LIMITATIONS}

A major limitation of this study is that there is no assurance that the patients were told to take all the drugs on the current medication lists, or that they actually took the medications. It is possible that some of the drugs on the list, although listed as active, were not intended to be continued and should have been removed from the list during medication reconciliation. A home visit or thorough medication reconciliation during an ambulatory visit would provide a more accurate measure of the prevalence of potential multidrug interactions [2]. Nevertheless, the fact that the potentially interacting drugs are on the active medication lists, even if not taken by the patients, may demonstrate inattention of the clinicians as to what other medications have been prescribed, as well as incomplete medication reconciliation. Medication discrepancies have been well documented and often occur during transition to nursing facilities [39, 40].

A second limitation is that the measurements of prevalence of three and four multidrug interactions are specific to NYP. The NYP-computerized physician order entry system has a drug-drug interaction prompt that utilizes the NYP-Multum database. The identification and rating of various interactions might differ across institutions given that there is little agreement across the various drug-interaction databases [41-45]. Furthermore, if NYP physicians were more (or less) responsive to interaction warning prompts, then the observed prevalence of the multidrug interactions might be lower (or higher) than that observed at other institutions. Thus, the prevalence rate, too, is institution specific.

A third limitation is that we did not take into consideration the doses of the medications that were involved in the potential multidrug interactions. It is possible that patients were prescribed lower doses of a particular medication than recommended because a second or third drug could influence its metabolism, thus mitigating any potentially amplifying interaction.

\section{CONCLUSIONS}

The current rating of the severity of drug-drug interactions is based on drug-drug pairs and does not consider multidrug interactions in which amplification may increase the likelihood of an associated adverse event. Using network analysis of ambulatory patients' current medication lists, we identified potential multidrug interactions that, acting through pharmacodynamic, pharmacokinetic and conditional mechanisms, expose patients to amplified risks of serious adverse events. Psychotropic drugs, known to cause sudden death and serotonin syndrome, were the most common drugs involved in the multidrug interactions identified. Estimating risk of drug-related adverse events should be adjusted for potentially amplifying multidrug interactions.

\section{ACKNOWLEDGMENTS}

The authors are deeply grateful to Matthew Spotnitz, MD for his meticulous review of the manuscript and insightful comments.

\section{DECLARATIONS}

Funding: Tara V. Anand was chosen as a Clare Booth Luce Scholar and supported by a grant from Barnard College, Columbia University.

Conflicts of interest/Competing interests : NA

Availability of data and material : Not available because of HIPAA guidelines

Code availability : NA; code is published

Authors' contributions All authors contributed to the study conception and design. Material preparation, data collection and analysis were performed by Tara V. Anand, Brendan K. Wallace and Herbert S. Chase. 
The first draft of the manuscript was written by Herbert S. Chase and all authors commented on previous versions of the manuscript. All authors read and approved the final manuscript.

\section{REFERENCES}

1. Becker ML. Hospitalisations and emergency department visits due to drug-drug interactions: a literature review. Pharmacoepidemiology and drug safety. 2007;16(6):641-51. doi:10.1002/pds.1351.

2. Kantor ED, Rehm CD, Haas JS, Chan AT, Giovannucci EL. Trends in prescription drug use among adults in the united states from 1999-2012. JAMA. 2015;314(17):1818-30. doi:10.1001/jama.2015.13766.

3. Masnoon N, Shakib S, Kalisch-Ellett L, Caughey GE. What is polypharmacy? A systematic review of definitions. BMC Geriatr. 2017;17(1):230-. doi:10.1186/s12877-017-0621-2.

4. Björkman IK. Drug-drug interactions in the elderly. The Annals of pharmacotherapy. 2002;36(11):1675-81. doi:10.1345/aph.1A484.

5. Sutherland JJ, Daly TM, Liu X, Goldstein K, Johnston JA, Ryan TP. Co-prescription trends in a large cohort of subjects predict substantial drug-drug interactions. PloS one. 2015;10(3):e0118991-e. doi:10.1371/journal.pone.0118991.

6. Roughead EE. Multidrug interactions: the current clinical and pharmacovigilance challenge. Journal of Pharmacy Practice and Research. 2015;45(2):138-9. doi:10.1002/jppr.1101.

7. Xiang Y, Albin A, Ren K, Zhang P, Etter JP, Lin S et al. Efficiently mining Adverse Event Reporting System for multiple drug interactions. AMIA Joint Summits on Translational Science proceedings AMIA Joint Summits on Translational Science. 2014;2014:120-5.

8. Tulner LR. Drug-drug interactions in a geriatric outpatient cohort: prevalence and relevance. Drugs \& aging. 2008;25(4):343-55. doi:10.2165/00002512-200825040-00007.

9. Aljadani R, Aseeri M. Prevalence of drug-drug interactions in geriatric patients at an ambulatory care pharmacy in a tertiary care teaching hospital. BMC research notes. 2018;11(1):234-. doi:10.1186/s13104-018$3342-5$.

10. Cerner Solutions Drug Database. https://www.cerner.com/solutions/drug-database.

11. Tarjan R. Depth-First Search and Linear Graph Algorithms. SIAM Journal on Computing. 1972;1(2):14660. doi:10.1137/0201010.

12. Gandhi TK, Weingart SN, Borus J, Seger AC, Peterson J, Burdick E et al. Adverse drug events in ambulatory care. NEJM. 2003;348(16):1556-64.

13. Khalil H, Huang C. Adverse drug reactions in primary care: a scoping review. BMC health services research. 2020;20(1):5-. doi:10.1186/s12913-019-4651-7.

14. Laatikainen O, Sneck S, Bloigu R, Lahtinen M, Lauri T, Turpeinen M. Hospitalizations Due to Adverse Drug Events in the Elderly-A Retrospective Register Study. Frontiers in Pharmacology. 2016;7(358). doi:10.3389/fphar.2016.00358.

15. Obreli-Neto PR, Nobili A, de Oliveira Baldoni A, Guidoni CM, de Lyra Júnior DP, Pilger D et al. Adverse drug reactions caused by drug-drug interactions in elderly outpatients: a prospective cohort study. Eur J Clin Pharmacol. 2012;68(12):1667-76. doi:10.1007/s00228-012-1309-3.

16. Holm J, Eiermann B, Eliasson E, Mannheimer B. A limited number of prescribed drugs account for the great majority of drug-drug interactions. Eur J Clin Pharmacol. 2014;70(11):1375-83. doi:10.1007/s00228014-1745-3.

17. Létinier L, Cossin S, Mansiaux Y, Arnaud M, Salvo F, Bezin J et al. Risk of Drug-Drug Interactions in Out-Hospital Drug Dispensings in France: Results From the DRUG-Drug Interaction Prevalence Study. 
Frontiers in Pharmacology. 2019;10(265). doi:10.3389/fphar.2019.00265.

18. Mojtabai R, Olfson M. National Trends in Psychotropic Medication Polypharmacy in Office-Based Psychiatry. Archives of General Psychiatry. 2010;67(1):26-36. doi:10.1001/archgenpsychiatry.2009.175.

19. English BA, Dortch M, Ereshefsky L, Jhee S. Clinically significant psychotropic drug-drug interactions in the primary care setting. Curr Psychiatry Rep. 2012;14(4):376-90. doi:10.1007/s11920-012-0284-9.

20. Woosley RL, Heise CW, Gallo T, Tate J, Woosley D, K.A. R. QTdrugs List. AZCERT, Inc., 822 Innovation Park Dr., Oro Valley, AZ 85755. www.CredibleMeds.org.

21. Jeppesen U. Dose-dependent inhibition of CYP1A2, CYP2C19 and CYP2D6 by citalopram, fluoxetine, fluvoxamine and paroxetine. Eur J Clin Pharmacol. 1996;51(1):73-8. doi:10.1007/s002280050163.

22. Spina E, Santoro V, D'Arrigo C. Clinically relevant pharmacokinetic drug interactions with second-generation antidepressants: An update. Clinical Therapeutics. 2008;30(7):1206-27. doi:https://doi.org/10.1016/S0149-2918(08)80047-1.

23. Boyce RD. Age-related changes in antidepressant pharmacokinetics and potential drug-drug interactions: a comparison of evidence-based literature and package insert information. The American journal of geriatric pharmacotherapy.10(2):139-50. doi:10.1016/j.amjopharm.2012.01.001.

24. Frommeyer G, Fischer C, Ellermann C, Dechering DG, Kochhäuser S, Lange PS et al. Additive Proarrhythmic Effect of Combined Treatment with QT-Prolonging Agents. Cardiovascular Toxicology. 2018;18(1):84-90. doi:10.1007/s12012-017-9416-0.

25. Ray WA, Stein CM, Murray KT, Fuchs DC, Patrick SW, Daugherty J et al. Association of Antipsychotic Treatment With Risk of Unexpected Death Among Children and Youths. JAMA Psychiatry. 2019;76(2):16271. doi:10.1001/jamapsychiatry.2018.3421.

26. Danielsson B, Collin J, Jonasdottir Bergman G, Borg N, Salmi P, Fastbom J. Antidepressants and antipsychotics classified with torsades de pointes arrhythmia risk and mortality in older adults - a Swedish nationwide study. British journal of clinical pharmacology. 2016;81(4):773-83. doi:10.1111/bcp.12829.

27. Sicouri S. Sudden cardiac death secondary to antidepressant and antipsychotic drugs. Expert opinion on drug safety.7(2):181-94. doi:10.1517/14740338.7.2.181.

28. Ray WA, Chung CP, Murray KT, Hall K, Stein CM. Atypical Antipsychotic Drugs and the Risk of Sudden Cardiac Death. NEJM. 2009;360(3):225-35. doi:10.1056/NEJMoa0806994.

29. Schneeweiss S, Avorn J. Antipsychotic Agents and Sudden Cardiac Death - How Should We Manage the Risk? NEJM. 2009;360(3):294-6. doi:10.1056/NEJMe0809417.

30. Risgaard B. Sudden cardiac death in young adults with previous hospital-based psychiatric inpatient and outpatient treatment: a nationwide cohort study from Denmark. The Journal of Clinical Psychiatry. 2015;76(9):e1122-9. doi:10.4088/JCP.14m09742.

31. Simpson TF, Salazar JW, Vittinghoff E, Probert J, Iwahashi A, Olgin JE et al. Association of QTProlonging Medications With Risk of Autopsy-Defined Causes of Sudden Death. JAMA Internal Medicine. 2020. doi:10.1001/jamainternmed.2020.0148.

32. Zhu J, Hou W, Xu Y, Ji F, Wang G, Chen C et al. Antipsychotic drugs and sudden cardiac death: A literature review of the challenges in the prediction, management, and future steps. Psychiatry Research. 2019;281:112598. doi:https://doi.org/10.1016/j.psychres.2019.112598.

33. Zheng WY, Richardson LC, Li L, Day RO, Westbrook JI, Baysari MT. Drug-drug interactions and their harmful effects in hospitalised patients: a systematic review and meta-analysis. Eur J Clin Pharmacol. 2018;74(1):15-27. doi:10.1007/s00228-017-2357-5. 
34. Sánchez-Fidalgo S, Guzmán-Ramos MI, Galván-Banqueri M, Bernabeu-Wittel M, Santos-Ramos B. Prevalence of drug interactions in elderly patients with multimorbidity in primary care. Int J Clin Pharm. 2017;39(2):343-53. doi:10.1007/s11096-017-0439-1.

35. Marusic S, Bacic-Vrca V, Obreli Neto PR, Franic M, Erdeljic V, Gojo-Tomic N. Actual drug-drug interactions in elderly patients discharged from internal medicine clinic: a prospective observational study. Eur J Clin Pharmacol. 2013;69(9):1717-24. doi:10.1007/s00228-013-1531-7.

36. Smithburger PL. Drug-drug interactions in cardiac and cardiothoracic intensive care units: an analysis of patients in an academic medical centre in the US. Drug safety. 2010;33(10):879-88. doi:10.2165/11532340000000000-00000.

37. Bucşa C. How many potential drug-drug interactions cause adverse drug reactions in hospitalized patients? European journal of internal medicine. 2013;24(1):27-33. doi:10.1016/j.ejim.2012.09.011.

38. Fitzmaurice MG. Evaluation of Potential Drug-Drug Interactions in Adults in the Intensive Care Unit: A Systematic Review and Meta-Analysis. Drug safety. 2019;42(9):1035-44. doi:10.1007/s40264-019-00829-y.

39. Tjia J, Bonner A, Briesacher BA, McGee S, Terrill E, Miller K. Medication Discrepancies upon Hospital to Skilled Nursing Facility Transitions. J Gen Intern Med. 2009;24(5):630-5. doi:10.1007/s11606-009-0948-2.

40. Ekedahl A, Brosius H, Jönsson J, Karlsson H, Yngvesson M. Discrepancies between the electronic medical record, the prescriptions in the Swedish national prescription repository and the current medication reported by patients. Pharmacoepidemiology and Drug Safety. 2011;20(11):1177-83. doi:10.1002/pds.2226.

41. Olvey EL, Clauschee S, Malone DC. Comparison of Critical Drug-Drug Interaction Listings: The Department of Veterans Affairs Medical System and Standard Reference Compendia. Clinical Pharmacology \& Therapeutics. 2010;87(1):48-51. doi:10.1038/clpt.2009.198.

42. Schjøtt J. Analysis of consensus among drug interaction databases with regard to combinations of psychotropics. Basic \& clinical pharmacology \& toxicology. doi:10.1111/bcpt.13312.

43. Ayvaz S, Horn J, Hassanzadeh O, Zhu Q, Stan J, Tatonetti NP et al. Toward a complete dataset of drug-drug interaction information from publicly available sources. J Biomed Inform. 2015;55:206-17. doi:https://doi.org/10.1016/j.jbi.2015.04.006.

44. Muhič N, Mrhar A, Brvar M. Comparative analysis of three drug-drug interaction screening systems against probable clinically relevant drug-drug interactions: a prospective cohort study. Eur J Clin Pharmacol. 2017;73(7):875-82. doi:10.1007/s00228-017-2232-4.

45. Fung KW, Kapusnik-Uner J, Cunningham J, Higby-Baker S, Bodenreider O. Comparison of three commercial knowledge bases for detection of drug-drug interactions in clinical decision support. J Am Med Inform Assoc. 2017;24(4):806-12. doi:10.1093/jamia/ocx010.

Table 1 Expected and observed average number of drugs per patient with pDDIs on medication lists. The total number of patients with pDDIs was 5142 representing $23.3 \%$ of the 22033 total patients.

\begin{tabular}{llllll}
\hline & $\begin{array}{l}\text { \# drugs } \\
\text { \# pDDIs per } \\
\text { pDDIs (\% total } \\
\text { patient }\end{array}$ & $\begin{array}{l}\text { participating in } \\
\text { pDDI per } \\
\text { patient }\end{array}$ & $\begin{array}{l}\text { \#drugs } \\
\text { participating in } \\
\text { pDDI per } \\
\text { patient }\end{array}$ & $\begin{array}{l}\text { \# drugs on } \\
\text { medication list } \\
\text { (SD) }\end{array}$ & $\begin{array}{l}\% \text { all drugs } \\
\text { participating in } \\
\text { a DDI }\end{array}$ \\
\hline & & Expected & Actual (SD) & & \\
1 & $3369(15.9)$ & 2 & 2.0 & $7.77(3.13)$ & 25.7 \\
2 & $954(4.33)$ & 4 & $3.44(0.95)$ & $9.70(3.16)$ & 35.5 \\
3 & $456(2.07)$ & 6 & $4.11(0.95)$ & $10.45(3.34)$ & 39.3 \\
4 & $183(0.83)$ & 8 & $5.05(0.91)$ & $11.64(3.37)$ & 43.4 \\
5 & $93(0.42)$ & 10 & $5.71(1.31)$ & $13.11(4.56)$ & 43.5
\end{tabular}




\begin{tabular}{llllll}
\hline & & \#drugs & \#drugs & & \\
& \# Patients with & participating in & participating in & \# drugs on & \% all drugs \\
\# pDDIs per & pDDIs (\% total & pDDI per & pDDI per & $\begin{array}{l}\text { medication list } \\
\text { participating in }\end{array}$ & $\begin{array}{l}\text { (SD) } \\
\text { patient }\end{array}$ \\
\hline 6 & patients) & patient & patient & $13.38(3.94)$ & 46.3 \\
7 & $28(0.27)$ & 12 & $6.20(1.41)$ & $16.21(4.61)$ & 46.8 \\
\hline
\end{tabular}

Table 2 The number of interactions between individual drugs in pMDIs. The total number of pMDIs and interactions were 1129 and 3325 , respectively.

\begin{tabular}{|c|c|c|c|c|c|c|c|c|}
\hline \multicolumn{2}{|l|}{$\begin{array}{l}\text { Number of } \\
\text { interactions }\end{array}$} & \multirow{2}{*}{$\begin{array}{l}\begin{array}{l}\text { Number of } \\
\text { drugs }\end{array} \\
3\end{array}$} & \multirow{2}{*}{$\begin{array}{l}\text { Number of } \\
\text { drugs } \\
4\end{array}$} & \multirow{2}{*}{$\begin{array}{l}\text { Number of } \\
\text { drugs }\end{array}$} & \multirow{2}{*}{$\begin{array}{l}\text { Number of } \\
\text { drugs }\end{array}$} & \multirow{2}{*}{$\begin{array}{l}\begin{array}{l}\text { Number of } \\
\text { drugs }\end{array} \\
7\end{array}$} & \multirow{2}{*}{$\begin{array}{l}\begin{array}{l}\text { Number of } \\
\text { drugs }\end{array} \\
>=8\end{array}$} & \multirow{2}{*}{$\begin{array}{l}\begin{array}{l}\text { Numbe } \\
\text { drugs }\end{array} \\
\text { Total } \\
\text { interac }\end{array}$} \\
\hline & & & & & & & & \\
\hline & 2 & 610 & & & & & & 1220 \\
\hline & 3 & 142 & 150 & & & & & 876 \\
\hline & 4 & & 54 & 46 & & & & 400 \\
\hline & 5 & & 15 & 19 & 9 & & & 215 \\
\hline & 6 & & 14 & 6 & 14 & 11 & & 270 \\
\hline & 7 & & & 1 & 3 & 4 & 2 & 70 \\
\hline & 8 & & & 1 & 3 & 4 & 2 & 80 \\
\hline & 9 & & & 1 & 2 & 1 & 3 & 63 \\
\hline & 10 & & & 1 & 1 & 2 & 1 & 50 \\
\hline & 11 & & & & 0 & 2 & 2 & 44 \\
\hline & 12 & & & & 1 & 0 & 1 & 24 \\
\hline & 13 & & & & 0 & 1 & 0 & 13 \\
\hline$p M D I s$ & $p M D I s$ & 752 & 233 & 75 & 33 & 25 & 11 & \\
\hline $\begin{array}{l}\% \text { total } \\
\text { pMDIs (\%) }\end{array}$ & $\begin{array}{l}\% \text { total } \\
\text { pMDIs }(\%)\end{array}$ & 66.6 & 20.6 & 6.6 & 2.9 & 2.2 & 0.7 & \\
\hline
\end{tabular}

Table 3 Fifteen most common drugs and top drug classes involved in multidrug interactions. Aspirin was counted as an anticoagulant not NSAID.

\begin{tabular}{lllll}
\hline DRUG & CLASS & \% Total & TOP CLASSES & \% Total \\
\hline aspirin & anticoagulant & 4.4 & psychotropic & 23.3 \\
bupropion & psychotropic & 4.3 & anticoagulant & 10.9 \\
escitalopram & psychotropic & 3.6 & NSAID & 9.6 \\
tramadol & narcotic & 3.4 & narcotic & 7.4 \\
trazodone & psychotropic & 3.0 & antiarrhythmic & 4.8 \\
amiodarone & antiarrhythmic & 2.9 & antiemetic & 2.7 \\
ondansetron & antiemetic & 2.7 & antibiotic & 2.7 \\
oxycodone & narcotic & 2.3 & immunosuppressant & 2.7 \\
warfarin & anticoagulant & 2.2 & diuretic & 2.4 \\
mirtazapine & psychotropic & 1.9 & beta-blocker & 2.5 \\
duloxetine & psychotropic & 1.9 & chemotherapeutic & 1.9 \\
methotrexate & chemotherapeutic & 1.9 & muscle relaxant & 1.5 \\
clopidogrel & anticoagulant & 1.7 & PPI & 1.3 \\
apixaban & anticoagulant & 1.7 & beta-agonist & 1.2
\end{tabular}




\begin{tabular}{lllll}
\hline DRUG & CLASS & \% Total & TOP CLASSES & $\%$ Total \\
\hline diclofenac & NSAID & 1.7 & statin & 1.0 \\
\hline
\end{tabular}

Table 4 List of pADEs associated with pMDIs. The total number of pMDIs with each of the different pADE-instances listed in the first column. The total number of pMDIs where two or more instances of the same pADE are listed in the second column

\begin{tabular}{lll}
\hline pADE-instances & Number of pMDIs & Number of pMDIs \\
\hline & All (\% total) & Two or more (\% total) \\
serotonin syndrome & $384(17.2)$ & $191(15.7)$ \\
seizure & $319(14.4)$ & $236(19.4)$ \\
QT & $351(15.8)$ & $198(16.3)$ \\
bleeding OR hemorrhage & $319(14.4)$ & $205(16.9)$ \\
nephrotoxic, renal failure & $183(8.2)$ & $91(7.5)$ \\
hepatotoxicity & $112(5.0)$ & $55(4.5)$ \\
bronchospasm & $70(3.2)$ & $40(3.3)$ \\
myopathy, rhabdomyolysis & $74(3.3)$ & $34(2.8)$ \\
sinus arrest & $44(2.0)$ & $44(3.6)$ \\
risk of infection & $66(3.0)$ & $29(2.4)$ \\
produce hypokalemia & $82(3.7)$ & $21(1.7)$ \\
bradycardia & $70(3.2)$ & $27(2.2)$ \\
ulceration & $47(2.2)$ & $28(2.3)$ \\
tendon rupture & $36(1.6)$ & $13(1.1)$ \\
AV block & $16(0.7)$ & $2(0.2)$ \\
reduced myocardial contractility & $20(0.9)$ & $0(0.0)$ \\
TOTALS & $\mathbf{2 2 2 2}$ & $\mathbf{1 2 1 4}$ \\
\hline
\end{tabular}

Table 5 The number of pMDIs with a single pADE-instance or two or more pADE-instances.

\begin{tabular}{lllll}
\hline Number of drugs in pMDIs & 3 & 3 & 4 & 4 \\
\hline TOTAL pMDIs & 752 & 752 & 233 & 233 \\
Number of pMDIs with a single instance of an associated pADE & 174 & $23.1 \%$ & 17 & $7.3 \%$ \\
Number of pMDIs with two or more instances of the same pADE & 578 & $76.9 \%$ & 216 & $92.7 \%$ \\
\hline
\end{tabular}

TABLE 6 Examples of amplification of pADEs in pMDIs. SS = serotonin syndrome; pQT = prolonged QT interval; SP: seizures; LSP = lowers seizurogenic potential; HEM = hemorrhage; HK = hypokalemia; HCTZ $=$ hydrochlorothiazide; MET $=$ metabolism.

\begin{tabular}{lllll}
\hline & $\begin{array}{l}\text { Medication } \\
\text { list drugs }\end{array}$ & $\begin{array}{l}\text { Drug-drug } \\
\text { pairs }\end{array}$ & pADE & Pharmacokinetic PharmacodynamicConditional \\
\hline A & $\begin{array}{l}\text { edoxaban, } \\
\text { meloxicam, } \\
\text { dabigatran }\end{array}$ & $\begin{array}{l}\text { edoxaban, } \\
\text { meloxicam }\end{array}$ & HEM & $\begin{array}{l}\text { All drugs } \\
\text { (HEM) }\end{array}$ \\
& $\begin{array}{l}\text { meloxicam, } \\
\text { dabigatran } \\
\text { dabigatran, } \\
\text { edoxaban }\end{array}$ & HEM & & \\
& & &
\end{tabular}




\begin{tabular}{|c|c|c|c|c|c|}
\hline & $\begin{array}{l}\text { Medication } \\
\text { list drugs }\end{array}$ & $\begin{array}{l}\text { Drug-drug } \\
\text { pairs }\end{array}$ & $p A D E$ & Pharmacokinetic & PharmacodynamicConditional \\
\hline \multirow[t]{3}{*}{ B } & $\begin{array}{l}\text { tramadol, } \\
\text { ondansetron, } \\
\text { citalopram }\end{array}$ & $\begin{array}{l}\text { tramadol, } \\
\text { ondansetron }\end{array}$ & SS & & $\begin{array}{l}\text { All drugs } \\
\text { (SS); } \\
\text { ondansetron } \\
\text { and } \\
\text { citalopram } \\
\text { (pQT); } \\
\text { tramadol } \\
\text { and } \\
\text { citalopram } \\
\text { (SP) }\end{array}$ \\
\hline & & $\begin{array}{l}\text { ondansetron, } \\
\text { citalopram }\end{array}$ & $\mathrm{pQT}, \mathrm{SS}$ & & \\
\hline & & $\begin{array}{l}\text { citalopram, } \\
\text { tramadol }\end{array}$ & $\mathrm{SP} ; \mathrm{SS}$ & & \\
\hline \multirow[t]{3}{*}{$\mathrm{C}$} & $\begin{array}{l}\text { sotalol esci- } \\
\text { talopram, } \\
\text { alfuzosin }\end{array}$ & $\begin{array}{l}\text { sotalol, } \\
\text { escitalopram }\end{array}$ & pQT & & $\begin{array}{l}\text { All drugs } \\
\text { (pQT) }\end{array}$ \\
\hline & & $\begin{array}{l}\text { escitalopram, } \\
\text { alfuzosin }\end{array}$ & pQT & & \\
\hline & & $\begin{array}{l}\text { alfuzosin, } \\
\text { sotalol }\end{array}$ & $\mathrm{pQT}$ & & \\
\hline \multirow[t]{5}{*}{$\mathrm{D}$} & $\begin{array}{l}\text { ketoconazole, } \\
\text { escitalo- } \\
\text { pram, } \\
\text { tramadol, } \\
\text { azithromycin }\end{array}$ & $\begin{array}{l}\text { ketoconazole, } \\
\text { escitalopram }\end{array}$ & pQT & $\begin{array}{l}\text { ketoconazole } \\
\text { inhibits } \\
\text { escitalopram } \\
\text { MET }\end{array}$ & $\begin{array}{l}\text { escitalopram } \\
\text { and } \\
\text { azithromycin } \\
\text { (pQT) } \\
\text { escitalopram } \\
\text { and } \\
\text { tramadol } \\
\text { (SS) }\end{array}$ \\
\hline & & $\begin{array}{l}\text { escitalopram, } \\
\text { tramadol }\end{array}$ & SS & & \\
\hline & & $\begin{array}{l}\text { escitalopram, } \\
\text { azithromycin }\end{array}$ & pQT & & \\
\hline & & $\begin{array}{l}\text { warfarin, } \\
\text { amiodarone }\end{array}$ & HEM & & \\
\hline & & $\begin{array}{l}\text { warfarin, } \\
\text { metronidazole }\end{array}$ & HEM & & \\
\hline \multirow[t]{3}{*}{$\mathrm{E}$} & $\begin{array}{l}\text { aspirin, } \\
\text { warfarin, } \\
\text { amiodarone, } \\
\text { metronidazole }\end{array}$ & $\begin{array}{l}\text { aspirin, } \\
\text { warfarin }\end{array}$ & HEM & $\begin{array}{l}\text { amiodarone } \\
\text { and metron- } \\
\text { idazole } \\
\text { inhibit } \\
\text { warfarin } \\
\text { MET }\end{array}$ & $\begin{array}{l}\text { aspirin and } \\
\text { warfarin } \\
\text { predispose } \\
\text { to HEM }\end{array}$ \\
\hline & & $\begin{array}{l}\text { warfarin, } \\
\text { amiodarone }\end{array}$ & HEM & & \\
\hline & & $\begin{array}{l}\text { warfarin, } \\
\text { metronidazole }\end{array}$ & HEM & & \\
\hline
\end{tabular}




\begin{tabular}{|c|c|c|c|c|c|c|}
\hline & $\begin{array}{l}\text { Medication } \\
\text { list drugs }\end{array}$ & $\begin{array}{l}\text { Drug-drug } \\
\text { pairs }\end{array}$ & $p A D E$ & Pharmacokinetic & Pharmacodynam & ioConditional \\
\hline \multirow[t]{3}{*}{$\overline{\mathrm{F}}$} & $\begin{array}{l}\text { furosemide } \\
\text { amiodarone } \\
\text { HTCZ } \\
\text { ranolazine }\end{array}$ & $\begin{array}{l}\text { furosemide, } \\
\text { amiodarone }\end{array}$ & $\mathrm{pQT}$ & & $\begin{array}{l}\text { amiodarone } \\
\text { and ranolazine } \\
(\mathrm{pQT})\end{array}$ & $\begin{array}{l}\text { furosemide } \\
\text { and HCTZ } \\
\text { (HK) which } \\
\text { increases pQT } \\
\text { by amiodarone } \\
\text { and ranolazine }\end{array}$ \\
\hline & & $\begin{array}{l}\text { HCTZ- } \\
\text { amiodarone- }\end{array}$ & $\mathrm{pQT}$ & & & \\
\hline & & $\begin{array}{l}\text { amiodarone- } \\
\text { ranolazine }\end{array}$ & $\mathrm{pQT}$ & & & \\
\hline \multirow[t]{3}{*}{ G } & $\begin{array}{l}\text { fluoxetine } \\
\text { mirtazapine } \\
\text { bupropion }\end{array}$ & $\begin{array}{l}\text { fluoxetine, } \\
\text { mirtazapine }\end{array}$ & SS & $\begin{array}{l}\text { bupropion } \\
\text { inhibits } \\
\text { mirtazapine } \\
\text { and fluoxetine } \\
\text { MET }\end{array}$ & $\begin{array}{l}\text { fluoxetine and } \\
\text { mirtazapine } \\
\text { (SS) }\end{array}$ & $\begin{array}{l}\text { fluoxetine and } \\
\text { mirtazapine } \\
\text { LSP enhance } \\
\text { bupropion } \\
\text { (SP) }\end{array}$ \\
\hline & & $\begin{array}{l}\text { mirtazapine, } \\
\text { bupropion }\end{array}$ & $\mathrm{SP}$ & & & \\
\hline & & $\begin{array}{l}\text { bupropion, } \\
\text { fluoxetine }\end{array}$ & SP & & & \\
\hline \multirow[t]{2}{*}{$\mathrm{H}$} & $\begin{array}{l}\text { citalopram, } \\
\text { bupropion, } \\
\text { rilpivirine }\end{array}$ & $\begin{array}{l}\text { citalopram, } \\
\text { rilpivirine }\end{array}$ & $\mathrm{pQT}$ & $\begin{array}{l}\text { bupropion } \\
\text { inhibits } \\
\text { citalopram } \\
\text { MET }\end{array}$ & $\begin{array}{l}\text { citalopram } \\
\text { and } \\
\text { rilpivirine } \\
\text { (pQT) }\end{array}$ & $\begin{array}{l}\text { Citalopram } \\
\text { (LSP); } \\
\text { bupropion } \\
\text { (SP) }\end{array}$ \\
\hline & & $\begin{array}{l}\text { citalopram, } \\
\text { bupropion }\end{array}$ & SP & & & \\
\hline
\end{tabular}

Fig. 1 Schematic of method used to identify potential multidrug interactions (pMDIs) and associated potential adverse drug events (pADEs). Step 1: each drug-drug pair in the drug-drug interaction table from NYP was represented as a Set $(A)$ and numbered consecutively (Set $A_{1}$, Set $A_{2} \ldots$ ) Step 2: a unique MEDLIST set (Set $B$ ) was generated for each patient and included all the medications on the patient's list. The $B$ sets of each patient's medications list were numbered consecutively (Set $B_{1}$, Set $B_{2} \ldots$ ). Step 3: For each Set $A_{\mathrm{n}}$ in the DRUG-DRUG INTERACTION TABLE, we checked to see if it was a subset of the patient's MED-LIST, Set $B_{n}$. Step 4: Overlapping drug-drug pairs were identified using network analysis. Step 5: potential ADEs associated with pMDIs were identified by consulting the NYP drug-drug interaction table which includes a detailed description of adverse event associated with a particular drug-drug interaction.

\section{Hosted file}

image1.emf available at https://authorea.com/users/376858/articles/493699-potentialmultidrug-interactions-in-elderly-ambulatory-patients 


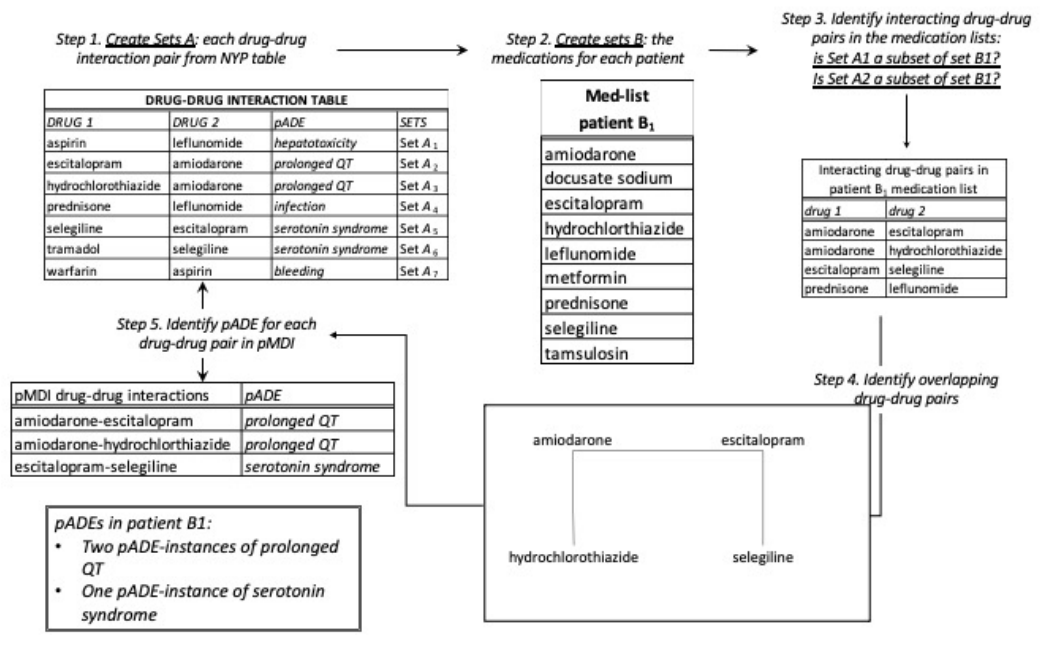

